\title{
Formulación de las NIF en México: referente de convergencia a NIIF
}

\author{
Development of the FRS in Mexico: concerning converge to IFRS
}

Formulation des NIF au Méxique: référent de convergence à NIIF

Helda María Fuentes Gómez

heldamaria_5@hotmail.com

Carrera 2 Este 64-169

Universidad de Boyacá

Tunja-Colombia

Contadora Pública, integrante fundadora del Semillero

INDECONT del Programa de Contaduría Pública, Universidad de Boyacá - Colombia.

Yudy Yamile Castiblanco Pinto yycastiblanco87@hotmail.com Carrera 2 Este 64-169 Universidad de Boyacá Tunja-Colombia

Estudiante X Semestre del Programa de Contaduría Pública de la Universidad de Boyacá. Integrante fundadora Semillero INDECONT.

Maricela Ramírez mramirez@uniboyaca.edu.co Carrera 2 Este 64-169 Universidad de Boyacá Tunja-Colombia

Magister en Administración Económica y Financiera, Contadora Pública, Docente Coordinadora del Semillero INDECONT del Programa de Contaduría Pública de la Universidad de Boyacá.

Artículo: Tipo de reflexion Según Clasificación Colciencias

Fecha de recepción: 20 de enero de 2011 Fecha de corrección: o9 de junio de 2011 Fecha de aprobación: 22 de junio de 2011

\section{Resumen}

El presente artículo se desarrolla en un momento coyuntural de la profesión contable a nivel mundial, debido a que las Normas Internacionales de Información Financiera (NIIF) han cobrado gran importancia desde su creación, "como normatividad contable universal reconocida por las empresas, que permite cada vez más comparar la información financiera entre entidades de un mismo sector, aunque la base de sus negocios se encuentre en diferentes países, "destaca Alberto del Castillo Socio de Auditoria de la firma Price Wáter House Coopers". El resultado de la aplicación de estas normas permitirá que las decisiones de inversión se agilicen y los mercados actúen con rapidez, permitiendo un mayor volumen de operaciones. (Pérez, 2009).

De cara a esta realidad, Colombia a través de la Ley 1314 de 2009, a partir del 1 de enero del año 2010, inicia el proceso de convergencia hacia las NIIF delegando al Consejo Técnico de la Contaduría Pública (CTCP) como ente normalizador. De esta manera, para la profesión contable colombiana resulta conveniente dar una mirada a países que han desarrollado procesos similares, como lo es, el caso mexicano. Dado que México inició este proceso desde el año 2002 construyendo su cuerpo normativo contable denominado NIF (Normas de Información Financiera de México) sin perder de vista las NIIF (Normas Internacionales de Información Financiera) emitidas por la IASB (Junta de Normas Internacionales de Contabilidad).

Palabras clave: Consejo Mexicano de Normas de Información Financiera, Instituto Mexicano de Contadores Públicos, convergencia contable, Consejo Técnico de la Contaduría Pública. 


\section{Development of the FRS in Mexico: concerning converge to IFRS}

\author{
Formulación de las NIF en México: \\ referente de convergencia a NIIF
}

Formulation des NIF au Méxique: référent de convergence à NIIF

\section{Abstract}

This article develops a conjunctural moment of the accounting profession worldwide, due to International Financial Reporting Standards (IFRS) have become very important since its creation, "as universally recognized accounting standards by companies, allowing each again compare the financial information between entities in the same sector, although the basis of their business is in different countries", "stands Alberto del Castillo audit partner of PricewaterhouseCoopers." The result of the application of these standards will allow the investment decisions are expedited and the markets move quickly, allowing a greater volume of transactions. (Pérez, 2009).

Facing this reality, Colombia through Law 1314 of 2009, from 1 January 2010, begins the process of convergence to IFRS by delegating to the Technical Board of Public Accountancy (CTCP) and entity normalizer. Thus, for the accounting profession in Colombia is convenient to take a look at countries that have developed similar processes, such as the Mexican case. Since Mexico began this process since 2002 building its accounting regulatory body called FRS (Financial Reporting Standards in Mexico) without losing sight of the IFRS (International Financial Reporting Standards) issued by the IASB (International Accounting Standards Board of Accounting).

Keywords: Mexican Council of Financial Reporting Standards, Mexican Institute of Public Accountants, accounting convergence, Technical Council of Public Accounts.

\section{Formulation des NIF au Méxique: référent de convergence à NIIF}

\author{
Formulación de las NIF en México: \\ referente de convergencia a NIIF \\ Development of the FRS in Mexico: \\ concerning converge to IFRS
}

\section{Résumée}

Cet article se développe lors d'un moment conjoncturel de la profession comptable dans le monde, vu que les Normes Internationales d'Information Financière (NIIF) ont acquis une grande importance à partir de leur création, "comme normativité comptable universelle reconnue par les entreprises, qui permet de comparer de plus en plus l'information financière entre des entités d'un même secteur, si bien que la base de leur business se trouve en différents pays", "souligne Alberto del Castillo, associé de Price water house Coopers". Le résultat de l'application de ces normes va permettre plus d'agilité sur les décisions d'investissement, et une plus grande vitesse d'action des marchés, ce qui apportera une croissance du volume des opérations. (Pérez, 2009).

Face à cette réalité, la Colombie a commencé, le 1er janvier 2010, avec la Loi 1314 de 2009, le processus de convergence vers les NIIF en délégant au Conseil Technique de la Comptabilité Publique (CTCP) le rôle de normalisateur. On a résolu que pour la profession comptable colombienne en résulte convenable de donner un regard sur les pays qui ont déjà développé des processus similaires, comme le cas mexicain. Le Mexique a commencé ce processus à partir de l'année 2002 au moment de la construction de son corps normatif comptable dénommé NIF (Normes d'Information Financière du Mexique) sans perdre de vue les NIIF (Normes Internationales de Formation Financière) émises par la IASB (International Accounting Standards Board).

Mots clef: Conseil Mexicain de Normes d'Information Financière, Institut Mexicain de Compteurs Publiques, convergence comptable, Conseil Technique de la Comptabilité Publique.

* Note du traducteur: en anglais (IFRS) International Financial Reporting Standards. 


\section{Formulación de las NIF en México: referente de convergencia a NIIF}

\section{Introducción}

La consolidación de mercados a nivel internacional ha obligado a los países a crear normas financieras sólidas que les permitan competir económicamente y generar dinámicas cambiarias de alcance mundial. No obstante, para lograr esta tarea, cada una de las naciones ha tenido que evolucionar en su estructura contable.

En México, país cuya normatividad contable ocupará la mayoría de este texto, se ha vivido una transformación, tanto en las entidades que rigen las normas contables, como en las leyes mismas. El ente encargado de la elaboración de la normatividad contable, es el Consejo Mexicano de Normas de Información Financiera (CINIF) ${ }^{1}$, reemplazando en esta función al Instituto Mexicano de Contadores Públicos (IMCP), entidad que por más de tres décadas estuvo encargada de la emisión de los Principios de Contabilidad Generalmente Aceptados y cuyos lineamientos rectores han sido "propugnar por la unificación de criterios y lograr la implementación y aceptación de normas, procedimientos y principios básicos de ética y actuación profesional por parte de sus asociados" (Muñoz, 2010).

El propósito de este texto es mostrar el camino recorrido por México en el proceso de convergencia hacia las Normas Internacionales de Información Financiera, analizando las características de este momento, tomando referentes valederos que sirvan al proceso de convergencia iniciado por Colombia a partir de la Ley 1314 de 2009 teniendo en cuenta que el CINIF ha elegido el camino de convergencia y no adopción de las NIIF (Pérez, 2011).

Para lograr este objetivo en el presente documento, en una primera parte se muestra la estructura del marco conceptual de las NIIF emitidas por la IASB y su repercusión en los cimientos contables a nivel mundial, en segunda instancia, se señala el proceso de formulación de las NIF emitidas por el CINIF mediante un proceso juicioso de auscultación, sus características, y evolución y en una tercera y última parte, se determinan ciertas características del sistema contable colombiano para evaluar la posibilidad de tomar como referente el caso mexicano en la elaboración del nuevo cuerpo normativo contable colombiano.

De antemano, las autoras agradecen la colaboración del Contador Público Martín Álvarez Ochoa, Director del Programa de Contaduría Pública de la Universidad de Colima, por sus valiosos aportes sobre el tema.

\section{Proceso de formulación de las NIF en México}

\subsection{Proceso de formulación de las NIIF}

Para entender el proceso de creación de las normas contables que rigen un país, es necesario dar un vistazo a las normas globales que regulan y armonizan la información financiera; se trata de las Normas Internacionales de Información Financiera (NIIF), un conjunto de parámetros expedidos por la IASB (International Accounting Standards Board), que aparecen como consecuencia de la globalización económica y la práctica de importación y exportación de bienes y servicios. Con la creación de las NIIF se busca una información financiera de mayor calidad y transparencia, "se determina la aplicación del proceso de la convergencia contable con el afán de contribuir a la construcción de parámetros normativos, que pretenden regular las actividades económicas de las naciones, estas normas intervienen dentro del sector social, educativo, empresarial, ambiental, entre otros". (Ferreira, 2010).

La internacionalización de normas contables se vive desde 1973 con la creación por parte de la Federación Internacional de Contadores (IFAC) del Comité Internacional de Estándares Internacionales de Contabilidad (IASC) como organismo mundial encargado de la emisión de Estándares Internacionales de Contabilidad (IAS, por sus iniciales en inglés- NIC, por sus siglas en

1. El Consejo Directivo en su sesión celebrada el 15 de febrero de 2011 y, posteriormente, la Asamblea de Asociados en Asamblea General Extraordinaria celebrada el 14 de marzo de 2011, aprobaron el cambio de nombre del “Consejo Mexicano para la Investigación y desarrollo de normas de Información Financiera, A.C. (CINIF)” al de “Consejo Mexicano de Normas de Información Financiera, A.C. (CINIF)". 
español). Los primeros IAS fueron publicados en 1975 y versan sobre revelación de las políticas contables (IAS 1) y, valuación y presentación de inventarios por el sistema de costo histórico (IAS 2). Hasta el año 2001 el IASC ha emitido 41 IAS, los cuales, en abril del mismo año, son recibidos por la IASB quien reemplaza al IASC en esta función, formulando los Estándares Internacionales de Información Financiera, (conocidos como IFRS por sus siglas en inglés y como NIIF en español). El término IFRS - NIIF comprende todas las normas adoptadas por la IASB, estas comprenden las IAS - NIC, las IFRS - NIIF y las interpretaciones de las IAS emitidas por el antiguo Comité de Interpretaciones de Estándares (SIC) ${ }^{2}$.

Ahora, dando una mirada al caso de México, este comienza un proceso de convergencia a los dictámenes emitidos por la IASB (Junta de Normas Internacionales de Contabilidad Financiera) cuerpo que dentro de la IASCF 3 (Fundación del Comité de Normas de Contabilidad Financiera) "tiene como función el desarrollo y emisión de los estándares para la presentación de los reportes financieros (IFRS o NIIF) incluyendo las interpretaciones y documentos relacionados como el marco conceptual para la preparación y presentación de estados financieros, entre otros" (Motta, 2010).

Es así, como en el año 2002 en el país azteca se estableció el Consejo Mexicano de Normas de Información Financiera (CINIF) como "un organismo independiente en su patrimonio y operación, con la finalidad de cubrir tres objetivos: desarrollar normas de información financiera, transparentes, objetivas y confiables relacionadas con el desempeño de las entidades económicas y gubernamentales, que sean de utilidad para los emisores y usuarios de información financiera" (CINIF, 2010).

El proceso de convergencia de las NIF dio su primer paso en el momento que el CID (Comité para la Investigación y el Desarrollo) comparó los principios de contabilidad de otros países con los principios propios de México con el fin de identificar similitudes pero en, especial, determinar las diferencias para ser analizadas y así dar paso al desarrollo de las NIF, siguiendo un proceso contencioso de análisis, conciliación y auscultación. El proceso de auscultación es el medio que se ha determinado para que todos los usuarios de la información conozcan el contenido de cada NIF y emitan una opinión profesional en cuanto a cada una, analizando cambios, ventajas, desventajas y apropiaciones que se tendrán en cuenta y modifican el contenido de la misma en el caso que sea necesario (CINIF, 2010).

México se ha caracterizado por ser un país de larga tradición de normas contables y reconoce la necesidad de ir hacia las Normas Internacionales de Información Financiera emitidas por la IASB, proceso que según entrevista realizada a William Biese Decker, miembro del CINIF, el camino de convergencia y no, adopción de las NIIF se da por las siguientes razones:

* La elaboración de las NIF bajo este proceso tienen en cuenta las características específicas del entorno económico y legal mexicano.

* La trayectoria y el camino recorrido en la elaboración de la normatividad contable mexicana es una base importante para la elaboración de las Normas de Información Financiera (NIF), pues, mientras las pocas entidades públicas en México se encuentran obligadas a adoptar las NIIF completas a partir de 2012, los miles y miles de entidades no públicas necesitan normas diseñadas para ellas, y las NIIF para PYMES que se publicaron por el IASB en 2009, no tienen el mismo reconocimiento y principios de valuación aplicables a todas las emisoras de información financiera cualquiera que sea su tamaño, sean o no entidades públicas.

Así mismo, el CINIF, en el libro "Convergencia de las NIF con las NIIF" señala que las NIIF para las PYMES se contraponen al marco conceptual vigente de las NIF y de las NIIF, razón por la que ha enviado una carta al IASB para plantear la posición respecto de estas diferencias. Basado en lo anterior, el CINIF considera que el camino de convergencia ha sido el más conveniente y apropiado.

2. El Comité de Interpretaciones del anterior IASC (Standing Interpretations Committee - SIC) se reconstituyó en diciembre del 2001 con la denominación International Financial Reporting Interpretations Comité (IFRIC). Desde el 1o de marzo del 2010 el IFRIC cambió su denominación por IFRS Interpretations Committee, Comité de Interpretaciones de las NIIF (IFRS, 2011). 
El CINIF es el encargado directo de desarrollar dicha normatividad y para lograrlo lleva a cabo procesos de investigación y auscultación entre la comunidad financiera y de negocios y otros sectores interesados dando como resultado la emisión de documentos llamados Normas de Información Financiera (NIF), Orientación a las Normas de Información Financiera (ONIF), siendo las mejoras un documento que incluye propuestas de cambios puntuales a las NIF, las INIF y las ONIF como aclaraciones y guías de implementación de las NIF (CINIF, 2011). La filosofía de las NIF es lograr por una parte, la convergencia de las normas locales utilizadas por los diversos sectores de la economía, y por otro lado, converger en el mayor grado posible con las Normas Internacionales de Información Financiera (NIIF) emitidas por el IASB.

Este plan de convergencia consiste en que las NIF mexicanas son revisadas y comparadas con las NIIF; las NIIF son consideradas para elaborar nuevas NIF y se busca una mejor solución contable para incrementar la transparencia. (CINIF, 2011).

\subsection{Creación de las NIF}

El Consejo Mexicano de Normas de Información Financiera (CINIF) es creado en mayo de 2002 como un organismo independiente, para lograr el proceso de convergencia de normas locales de contabilidad. "El CINIF tiene como reto mantenerse como un organismo líder en el desarrollo y mejoramiento de normas contables" (CINIF, 2010).
El CINIF cuenta con la asamblea de asociados integrada por la Asociación de Bancos de México, Asociación Mexicana de Intermediarios Bursátiles, Instituto Mexicano de Ejecutivos de Finanzas, Asociación Nacional de Facultades y Escuelas de Contaduría y Administración, Bolsa Mexicana de Valores, Comisión Nacional Bancaria y de Valores, Comisión Nacional de Seguros y Fianzas, Consejo Coordinador Empresarial, Instituto Mexicano de Contadores Públicos, Secretaría de la Función Pública, Secretaría de Hacienda y Crédito Público, y a partir del año 2004, participa la Asociación Mexicana de Instituciones de Seguro y el Consejo Mexicano de Hombres de Negocios (CINIF, 2010). (Figura 1).

La creación de las NIF se hace a través de un proceso de auscultación el cual tiene una secuencia que comienza con la publicación de los proyectos que elabora el Comité de Investigación y Desarrollo (CID) , se da paso a las opiniones de profesionales y usuarios en cada proceso, se indica el plazo que, como mínimo, debe ser de tres meses otorgado por el CINIF para enviar los comentarios concernientes, luego se realiza la discusión de los documentos mediante foros y conferencias abiertas a través de la pagina del CINIF, donde las observaciones hechas por medio de la Web se analizan por el CID y por el Comité Técnico Consultivo (CTC). Es de resaltar la importancia que se da a los comentarios que han realizado los usuarios de la información para luego proseguir con la aprobación de cada NIF. (Figura 2).

Fruto de este trabajo, el CINIF desarrolló una serie de normas y circulares que componen la

\section{Figura 1. Estructura del CINIF}

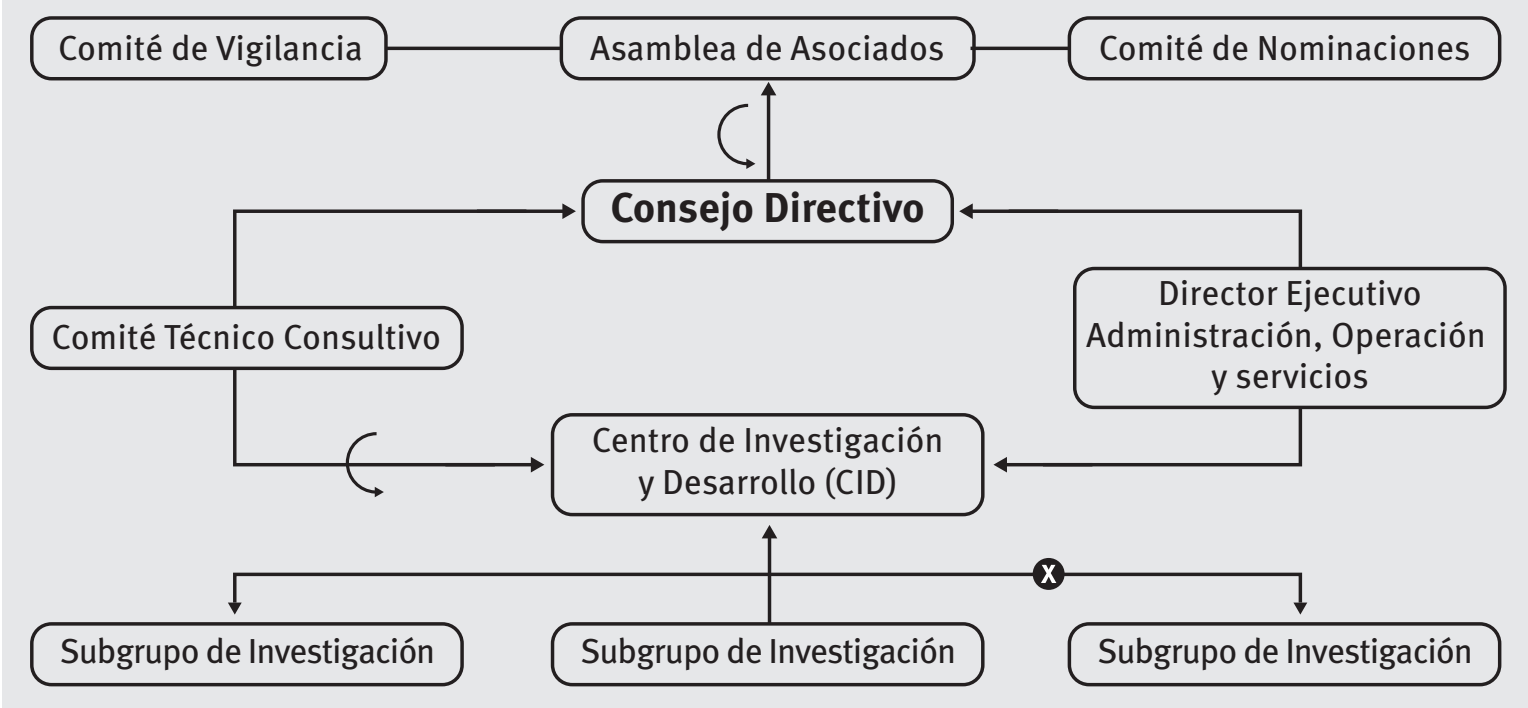




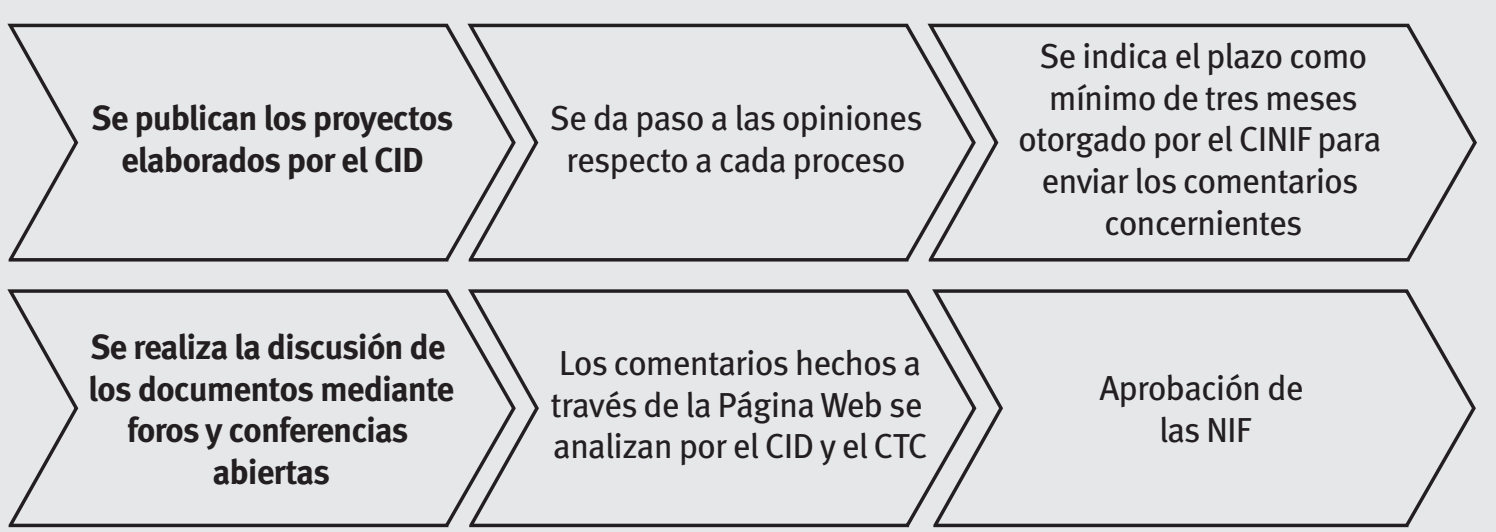

Fuente: elaboración propia.

estructura informativa contable y financiera en México, en 46 circulares divididas en 5 series, donde cada una de ellas determina el proceder para la presentación de informes en el territorio mexicano. El orden de creación de las NIF mexicanas es el siguiente:

\subsubsection{Creación NIF A}

\section{NIF Serie A}

NIF A1. Estructura de las Normas de Información Financiera. Esta norma señala el enfoque y la estructura de las NIF, una de sus características principales es que define el término contabilidad como "la técnica que se utiliza para el registro de las operaciones que afectan económicamente a una entidad y que produce sistemática y estructuralmente información financiera. Las operaciones que afectan económicamente a una entidad incluyen las transacciones, transformaciones internas y otros eventos" (Cobos, 2009).

La NIF A1 sienta las bases para el desarrollo de las demás normas, brindando una definición de las Normas de Información Financiera, como "el conjunto de pronunciamientos normativos, conceptuales y particulares, emitidos por el CINIF, los cuales regulan la información contenida en los estados financieros en un lugar y fecha determinados, y que son aceptados por todos los usuarios de la información financiera". Además, estructura el marco conceptual como un sistema coherente de objetivos y fundamentos interrelacionados, con un orden lógico deductivo destinado a servir como sustento racional en el desarrollo de las NIF. A continuación se presentan las siete normas siguientes de la serie A que, en resumen, tratan las siguientes temáticas:
NIF A2. Postulados Básicos. Estos son fundamentos que definen el ambiente en que deben operar los Sistemas de Información Contable (SIC). Los postulados de las NIF son:

* Sustancia económica: captación de la esencia económica, en la delimitación y operación del SIC.

* Entidad económica: identifica y delimita al ente.

* Negocio en marcha: asume la continuidad del ente económico.

* Devengación contable, asociación de costos, valuación, dualidad económica y consistencia: son los postulados que establecen las bases para el reconocimiento contable de las transacciones, transformaciones internas, y de los otros eventos que afectan económicamente a la entidad. (Cobos, 2009).

NIF A3. Necesidades de los usuarios y objetivos de los estados financieros. La tercera norma plantea tres definiciones:

* Entidad lucrativa: denominada como la unidad que desempeña actividades económicas combinando recursos humanos, materiales y financieros. Esta entidad cuenta con una autoridad encargada de tomar las decisiones con el ánimo de obtener fines de lucro.

* Entidad con propósitos no lucrativos: cuenta con la misma combinación de recursos que la anterior, su propósito es lograr beneficio social, sin resarcir económicamente a sus patrocinadores.

* Usuario general: interesados en la información financiera, conformado por: accionistas o dueños, patrocinadores, órganos de control, administradores, proveedores, acreedores, empleados, clientes, 
unidades gubernamentales, contribuyentes de impuestos, organismos reguladores y otros usuarios.

Debido a la gran cantidad de órganos que pueden estar interesados en los estados financieros, éstos deben propiciar todos los elementos de juicio confiables para evaluar el comportamiento económico de la entidad, su estabilidad y vulnerabilidad, además deben ser útiles para tomar decisiones de inversión, otorgamiento de créditos, rendimiento de los recursos.

Los estados financieros que responden a las necesidades del usuario general son clasificados así: balance general, el estado de resultados, el estado de variaciones en el capital contable y el estado de flujo de efectivo.

NIF A4. Características cualitativas de los estados financieros. La característica cualitativa fundamental del estado financiero es la utilidad, que es la posibilidad de adecuarse a las necesidades comunes del usuario general definido en la NIF anterior. La NIF 4 también señala cuatro características cualitativas primarias que son: confiabilidad, relevancia, la importancia relativa y la comparabilidad.

NIF A5. Elementos básicos de los estados financieros. Esta norma define los elementos básicos que componen un estado financiero; en las normas mexicanas se inicia definiendo el Balance General, un tipo de estado financiero que se compone de Activos, Pasivos y Capital o Patrimonio Contable.

Los Activos son todos los recursos que controla una entidad, son cuantificados en términos monetarios, y de ellos se espera beneficios económicos futuros. Los activos pueden ser Efectivo y Equivalente (Caja y Banco), Derechos a Recibir Efectivo (Cuentas por Cobrar), Derechos a recibir bienes (Anticipos a Proveedores) Bienes Disponibles para la Venta (Mercancías), Bienes destinados para su uso (Activos Fijos).

Los Pasivos son obligaciones presentes en la entidad, están representadas monetariamente y significan una disminución futura en términos económicos. Los Pasivos pueden ser: “Obligaciones de transferir efectivo (Cuentas por Pagar), Obligaciones de transferir Bienes (Anticipos a Clientes), Obligaciones de transferir instrumentos financieros emitidos por la propia entidad." (UADY, 2010).

El Capital contable es el valor residual de los activos de la entidad, una vez deducidos todos sus pasivos, puede ser capital contribuido por los apor- tes de los propietarios o capital ganado, conformado por las utilidades y pérdidas integrales acumuladas, así como las reservas creadas por los propietarios de la entidad.

NIF A6. Reconocimiento y Valuación. La sexta NIF enuncia los criterios generales que deben utilizarse en la valuación, en todas las transformaciones que hayan afectado económicamente a la entidad.

Esta norma define el reconocimiento contable como el proceso que consiste en valuar, presentar y revelar, en el sistema de información contable, los efectos de las transacciones, transformaciones internas que realiza una entidad, o todo tipo de evento que la afecte económicamente.

El reconocimiento contable debe cumplir con: originar una transacción de la entidad con otras entidades de transformaciones internas y de igual forma eventos pasados que le hayan representado afectación económica; también debe satisfacer la definición de estados financieros definidos en la NIF A5, debe ser cuantificable en términos monetarios.

Como puede observarse, la expedición de una Norma de Información Financiera atiende a las necesidades contables que el mercado requiere, son una cadena de cánones directamente relacionados, y donde el cumplimiento de una norma da, en la mayoría de los casos, el entendimiento y acatamiento de normas anteriores.

NIF A7. Presentación y revelación. La séptima NIF establece las normas generales aplicables a la presentación y revelación de información financiera que debe presentarse en los cuatro estados financieros básicos que por norma se deben presentar conjuntamente.

Se puede deducir que esta NIF, define el reconocimiento contable en el cual se debe basar una entidad para presentar los estados financieros y sus notas, en relación a las actividades desarrolladas.

NIF A8. Supletoriedad. La octava NIF establece que existe supletoriedad cuando la ausencia de normas de información financiera es cubierta por otro conjunto de normas distintas a las mexicanas, según normatividad contable, se toman por normas supletorias las NIF mexicanas; las NIIF, de no encontrar solución al problema, podrán recurrir a los normas de información financiera de Estados Unidos de América. 


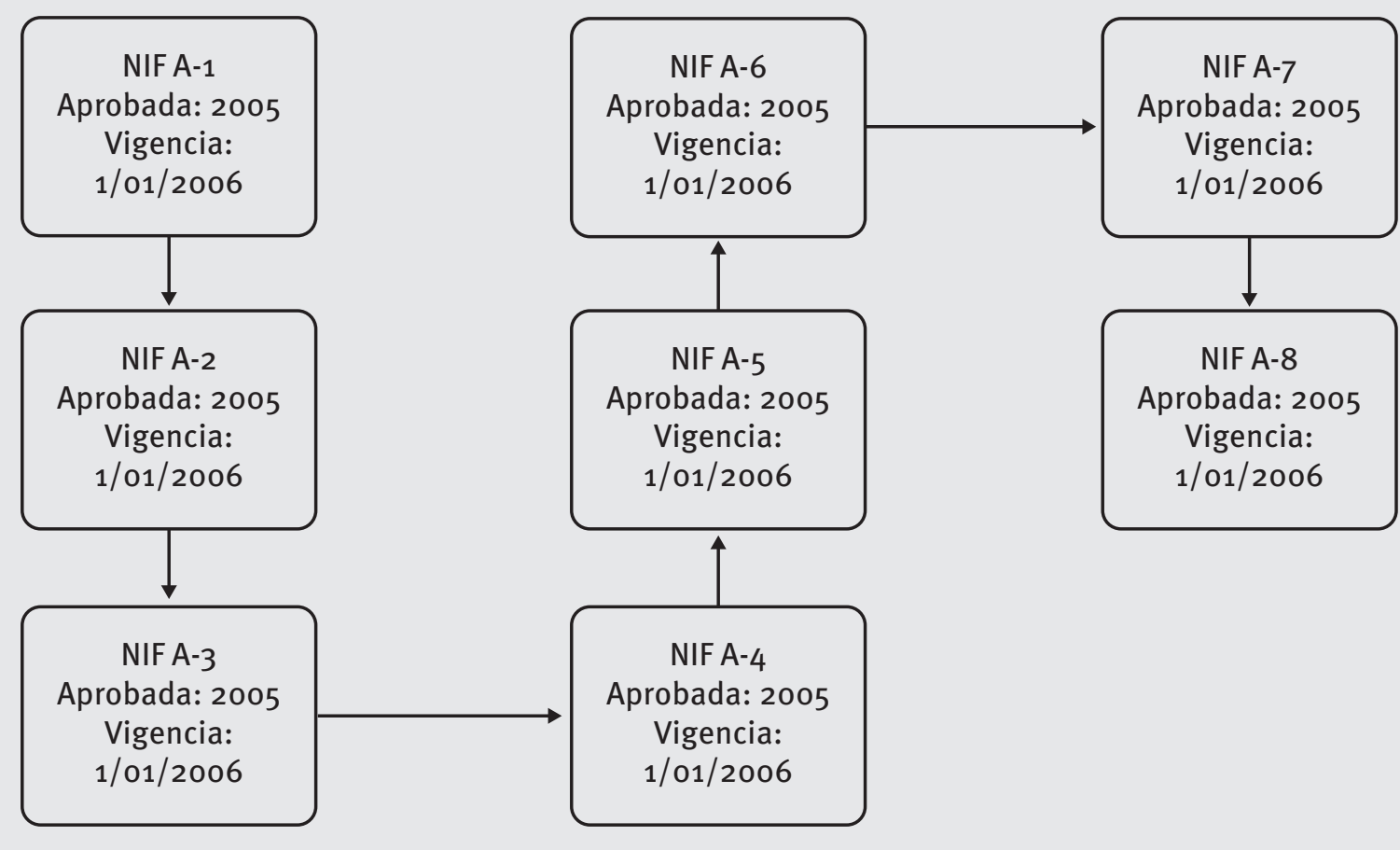

Fuente: CINIF, 2010.

\subsubsection{Creación NIF B}

\section{NIF SERIE B}

NIF B1. Cambios contables y correcciones de errores. La primera NIF B tiene como objetivo establecer normas particulares para el tratamiento y revelación de cambios contables de los estados financieros de todas las entidades. Un cambio contable se relaciona de la siguiente manera:

Cambio en la estructura del ente económico: surge con la modificación en el número de entidades que combinan o consolidan un ente económico y que permite que se revelen estados financieros que efectivamente son de una entidad diferente.

Cambio en estimación contable. Es el ajuste del valor actual en libros de un activo o de un pasivo resultante de su evaluación actual.

Cambio de una norma particular. Es la modificación de la aplicación de una norma derivada: por el cumplimiento de una NIF o por la emisión, modificación o derogación de una NIF (UNAM, 2010).

NIF B2. Estado de flujos de efectivo. La segunda NIF B tiene como objetivo presentar la forma de elaborar y presentar el estado de el estado de flujos de efectivo, basándose en unos parámetros y un procedimiento adecuado, para poder converger con la Norma Internacional de Información Financiera NIF 7 y es aplicable a todas las entidades que presentan estados financieros conforme a la NIF A-3 (Necesidades de los usuarios y objetivos de los estados financieros). Es importante resaltar que el estado de flujo de efectivo es un estado financiero básico.

NIF B3. Estado de resultados. La segunda NIF $B$ establece las normas generales para la presentación y estructura del estado de resultados y las normas de revelación, está NIF es aplicable a todas las entidades lucrativas.

NIF B4. Hechos posteriores a la fecha de los estados financieros. Los hechos posteriores presentan un esquema general que está compuesto por la fecha del balance general o corte del período y la fecha en que están autorizados los estados financieros para su emisión, que son los elementos primordiales que se tienen en cuenta para el período posterior que es el tiempo en el cual se pueden presentar los hechos posteriores a los estados financieros que están clasificados de la siguiente manera:

Con ajuste y revelación: son ocurridos en el período posterior y proporcionan mayor eviden- 
cia sobre condiciones financieras existentes a la fecha de los estados financieros.

Solamente revelación. Hechos ocurridos en el periodo posterior y que son indicativos de condiciones que surgieron después de la fecha de los estados financieros, sin embargo, por ser relevantes para la toma de decisiones se deben revelar.

Sin ajuste ni revelación. Son hechos posteriores que son indicativos de condiciones que surgieron después de la fecha de cierre y que no son relevantes para la toma de decisiones.

NIF B-5 Información financiera por segmentos. El CINIF emitió la NIF B-5 con la finalidad de converger con la NIIF 8. La NIF B-5 establece los criterios para identificar los segmentos sujetos a informar y las normas de revelación de dichos segmentos; también establece requerimientos de revelación de cierta información de la entidad económica en su conjunto. El enfoque gerencial que maneja la NIIF permite al usuario general analizar a una entidad desde el punto de vista de la administración.

NIF B-7. Adquisiciones de negocios. La NIF B-7 tiene por objeto establecer las normas para el reconocimiento inicial a la fecha de adquisición de los activos netos que se obtienen en una adquisición de negocios, de la participación no controladora y de las otras partidas que pueden surgir en la misma y las revelaciones correspondientes. Establece que la contraprestación pagada en una adquisición de negocios se valúe a su valor razonable en todos los casos. Asimismo, los gastos de compra y de reestructura no forman parte de la contraprestación, ya que no son parte del monto pagado a los dueños del negocio adquirido. Entre las modificaciones relevantes se encuentra el reconocimiento de la participación no controladora en la subsidiaria a valor razonable. Se establecen también las normas para el reconocimiento de activos readquiridos, pasivos contingentes, contraprestación contingente y activos para indemnización generados en la compra.

NIF B-8. Estados financieros consolidados 0 combinados. En esta nueva norma se precisa el tratamiento de las Entidades con Propósitos Específicos (EPE) que anteriormente no se definía claramente. También se incluye el nuevo tema de los derechos de voto potenciales, estableciendo que éstos deben considerarse cuando se evalúe la existencia de control. Después de evaluar cuidadosamente las modificaciones, el CINIF decidió no converger con la NIF en dos temas. En efecto, la NIC 27 establece que en los casos en que exista pérdida de control pero se mantenga parte o el total de la inversión permanente, se debe valuar la inversión a su valor razonable y determinar una ganancia o pérdida; el CINIF considera que no es válido usar el valor razonable ya que la inversión no ha sido negociada. Adicionalmente, esta NIF requiere que cuando se presenten estados financieros no consolidados se valúen las inversiones utilizando el método de participación, mientras que la NIC 27 da la opción de valuarlas a su costo de adquisición o de acuerdo con los lineamientos de la NIC 39, Instrumentos financieros: reconocimiento y valuación.

NIF B-9. Información financiera a fechas intermedias. La NIF B-9 se desarrolló con el objetivo de incorporar en la información financiera a fechas intermedias cambios provenientes de la emisión del Marco Conceptual y de otras NIF particulares. Adicionalmente, esta NIF se emite con la intención de converger con la NIC 34, Información financiera intermedia. La NIF B-9 contiene las normas de reconocimiento para la elaboración de la información financiera a fechas intermedias y el contenido de dicha información. Más específicamente, esta nueva NIF establece que la información financiera a fechas intermedias debe contener como mínimo, los siguientes estados financieros comparativos: un estado de posición financiera condensado; un estado de resultados o, en su caso, estado de actividades, condensado; si correspondiere, un estado de variaciones en el capital contable condensado; un estado de flujos de efectivo condensado y notas a los estados financieros con revelaciones seleccionadas.

NIF B-16. Estados financieros de entidades con propósitos no lucrativos. El CINIF decidió modificar el Boletín B-16, Estados financieros de entidades con propósitos no lucrativos, para incorporar la nueva terminología establecida en el Marco Conceptual de las NIF, en especial en las NIF A-3, Necesidades de los usuarios y objetivos de los estados financieros y A-5, Elementos básicos de los estados financieros; y para adicionar los cambios derivados del uso del estado de flujos de efectivo de acuerdo con la NIF B-2. Esta NIF contiene las normas generales para la elaboración y presentación de los estados financieros de las entidades con 
Aprobada: 2005

Vigencia:

1/01/2006
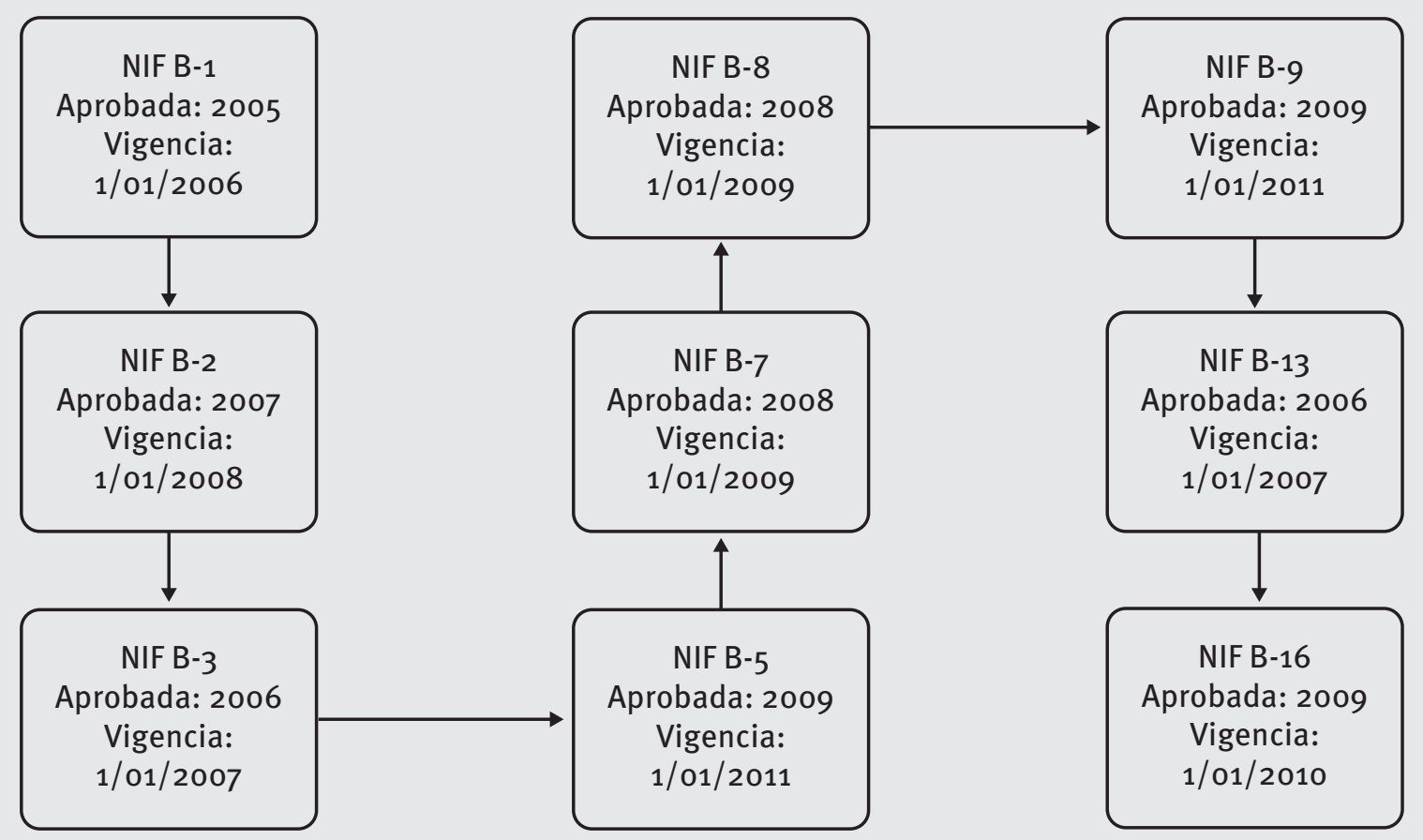

Fuente: CINIF, 2010.

propósitos no lucrativos y las revelaciones que deben hacerse. Los cambios importantes son: se incluye una sección de definiciones aplicables a las entidades con propósitos no lucrativos; se utiliza una clasificación de los activos, pasivos y patrimonio contable con base en lo establecido por el Marco Conceptual; se precisa que los donativos recibidos deben reconocerse como ingresos; se definen los principales niveles y clasificaciones del estado de actividades y se permite la presentación de los costos y gastos de acuerdo con su naturaleza (Figura 4).

\subsubsection{Creación NIF C}

\section{NIF SERIE C}

NIF C-1. Efectivo y equivalentes de efectivo. El CINIF modificó el Boletín C-1, Efectivo, con la finalidad de que sus disposiciones sean consistentes con la NIF B-2, Estado de flujos de efectivo y de converger con los conceptos de efectivo y equivalentes de efectivo contenidos en la Norma Internacional de Contabilidad 7.

Estado de flujos de efectivo (NIC 7). La NIF C-1 establece las normas de valuación, presentación y revelación de las partidas que integran el rubro de Efectivo y equivalentes de efectivo en el estado de posición financiera de una entidad.
Los principales cambios incluyen: el cambio de nombre de la NIF C-1 que ahora se denomina Efectivo y equivalentes de efectivo, ya no se pide que el efectivo y equivalentes de efectivo, restringidos se presenten en forma segregada; se sustituyó el término de inversiones temporales a la vista por el de inversiones disponibles a la vista y para identificar este tipo de inversiones, se incluye el que deben ser valores de disposición inmediata; se incluyen términos como costo de adquisición; equivalentes de efectivo; efectivo y equivalentes de efectivo, restringidos; inversiones disponibles a la vista; valor neto de realización; valor nominal y valor razonable.

NIF C-4. Inventarios. La NIF C-4 fue emitida por el CINIF para converger con la Norma Internacional de Contabilidad (NIC) 2, Inventarios. La NIF C-4 establece las normas de valuación, presentación y revelación para el reconocimiento inicial y posterior de los inventarios en el estado de posición financiera de las entidades económicas.

Los principales cambios que contiene esta nueva NIF son: se eliminan el costeo directo como un sistema de valuación y la fórmula (antes método) de asignación del costo de inventarios denominado últimas entradas-primeras salidas (“UEPS"); el costo de los inventarios debe ajustarse, los pagos anticipados relativos deben reconocerse como un gasto en los resultados del 
período o como un activo cuando se tenga la certeza de que los bienes o servicios adquiridos le generarán un beneficio económico futuro.

NIF C-5. Pagos anticipados. La principal razón para emitir la NIF C-5 fue el incorporar a ésta los nuevos conceptos y terminología establecida en el Marco Conceptual de las NIF. En las IFRS emitidas por el IASB no hay una norma que trate el tema de pagos anticipados por lo que no hay una IFRS con la cual converger. La NIF C-5 establece las normas de valuación, presentación y revelación de pagos anticipados en el estado de posición financiera.

Los principales cambios incluidos en esta NIF son: excluye de su alcance a los pagos anticipados que se tratan en otras NIF, tales como los impuestos a la utilidad, por activo neto proyectado derivado de un plan de pensiones y por intereses pagados por anticipado; establece como característica de los pagos anticipados el que éstos aún no transfieren a la entidad los beneficios y riesgos inherentes a los bienes 0 servicios que está por adquirir o recibir; los anticipos para la adquisición de inventarios o propiedades, planta y equipo, entre otros, deben presentarse en el rubro de pagos anticipados y no en los rubros de inventarios o de propiedades, planta y equipo, como se hacía con la anterior normativa; se establece que cuando un componente esté sin utilizar debe continuar depreciándose, salvo que se utilicen métodos de depreciación en función a la actividad.

NIF C-6. Propiedades, planta y equipo. El CINIF elaboró la NIF C-6 con la finalidad de converger con la Norma Internacional de Contabilidad (NIC) 16, Propiedades, planta y equipo, mejorar los criterios normativos del anterior Boletín C- 6 y actualizar las referencias al actual Marco Conceptual.

El objetivo de la NIF C- 6 es establecer las normas particulares de valuación, presentación y revelación relativas a las propiedades, planta, equipo, de tal forma que los usuarios de los estados financieros puedan conocer la información relativa a la inversión que la entidad tiene en propiedades, planta y equipo, así como los cambios ocurridos en esas inversiones. El CINIF decidió no modificar el enfoque básico o fundamental basado en el modelo del costo para el reconocimiento de las propiedades, planta y equipo, el cual es convergente con la NIC 16.
NIF C-7. Inversiones en asociadas y otras inversiones permanentes. La NIF C-7 tiene como objetivo establecer las normas para el reconocimiento contable de las inversiones en asociadas y otras inversiones permanentes en las que no se tiene control, control conjunto o influencia significativa. Como se mencionó anteriormente, la separación de las normas que se encontraban en el Boletín B-8, estados financieros consolidados y combinados y valuación de inversiones permanentes en acciones propició la creación de esta nueva NIF, que además, considera ya la terminología empleada en el MC. Al igual que la NIF B-8 incluye el tema de las EPE y de los derechos de votos potenciales con respecto a la determinación de la influencia significativa.

NIF C-8. Activos intangibles. El CINIF decidió modificar esta NIF durante el 2008, debido a que varios de los cambios realizados en la NIF B-7 causaron también modificaciones en temas relativos al reconocimiento del crédito mercantil y de los activos intangibles identificables en una adquisición de negocios junto con la determinación de su vida útil y amortización. También se adicionaron normas relativas a la asignación del crédito mercantil a las unidades a informar beneficiadas y los criterios para el reconocimiento de la investigación y desarrollo en proceso adquiridos en una adquisición de negocios; de tal forma que la NIF C-8 establece las normas de valuación, presentación y revelación para el reconocimiento inicial y posterior de los activos intangibles que se adquieren en forma individual o a través de una adquisición de negocios, o que se generen de forma interna en el curso normal de las operaciones de una entidad. Esta nueva NIF se encuentra en convergencia con lo establecido por la NIC 38, Activos intangibles.

NIF C-13. Partes relacionadas. La NIF amplia el concepto de las partes relacionadas incorporando las siguientes definiciones:

* Negocio conjunto: participa dentro de la entidad informante.

* Familiares cercanos: parte del personal gerencial clave o directivo relevante.

* Fondo: derivado de un plan de remuneraciones por obligaciones laborales. 


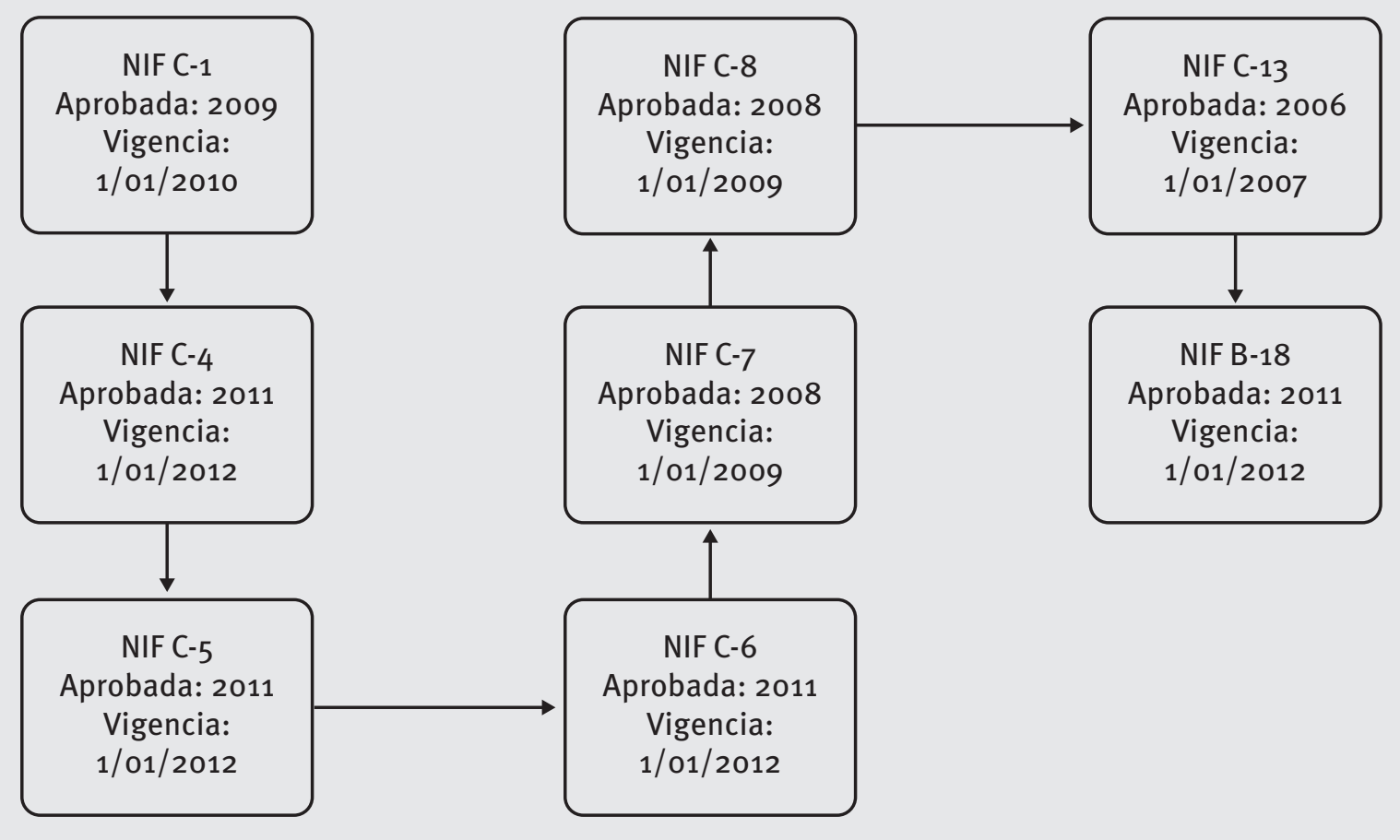

Fuente: CINIF, 2010.

Al entrar esta NIF en vigencia los estados financieros anteriores deben afectarse de manera retrospectiva, para revelar en sus notas las nuevas disposiciones de esta NIF, (Boletín Financiero, 2007).

NIF C-18. Obligaciones asociadas con el retiro de propiedades, planta y equipo.

El CINIF decidió emitir la NIF C-18 para completar las normas que identifican la metodología a utilizar para el reconocimiento de provisiones asociadas con el retiro de propiedades, planta y equipo, debido a que el Boletín C-9, Pasivo, provisiones, activos y pasivos contingentes y compromisos, no establece las condiciones que deben considerarse para la creación de esas provisiones. La NIF C-18 converge con la IFRIC 1 y se complementan los criterios normativos de la NIF C-8, Activos intangibles. La NIF C-18 incluye los siguientes cambios: los requisitos a considerar para la valuación de una obligación asociada con el retiro de un componente; el requerimiento de reconocer este tipo de obligaciones como una provisión; cómo reconocer los cambios a la valuación de estas provisiones; el uso de una tasa de descuento apropiada; el uso de la técnica de valor presente esperado; las revelaciones que una entidad debe presentar cuando tenga una obligación asociada con el retiro de un componente (Figura 5).

\subsubsection{Creación NIF D NIF SERIE D}

NIF D6. Capitalización del resultado final de financiamiento. Esta NIF va dirigida a todas las entidades cuya actividad principal sea la de tener inventarios que requieran de un período de adquisición prolongado para ponerlos en condiciones de venta.

NIF D-8. Pagos basados en acciones. La NIF D-8 obliga a las entidades a reconocer los costos o gastos incurridos, ya sea en resultados o como partida capitalizable y el correspondiente efecto en el pasivo o capital contable, por pagos basados en acciones, incluyendo el otorgamiento de opciones de compra de acciones a empleados.

El CINIF llevó a cabo este proyecto con la finalidad de normar un tema que no se encontraba contemplado en las NIF y que, por tanto, se aplicaba la supletoriedad observando la NIIF 2, Pagos basados en acciones. Por tanto, esta nueva NIF es convergente con lo establecido por la NIIF 2.

Según Martín Álvarez Ochoa, los rubros que presentan las mayores diferencias en el proceso de convergencia a NIIF son: Asociación de Costos y Gastos, Utilidades y dividendos, mantenimiento del capital, poca regulación en los reembolsos 
y en la reducción de capital, poca claridad en las estimaciones que se realizan, disparidad en los conceptos de inflación NIF B10-NIC 19, la valoración de los intangibles y los estados financieros obligatorios.

\section{Figura 6. NIF D}

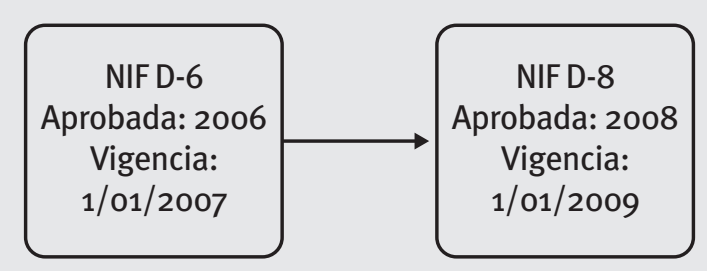

Fuente: CINIF, 2010.

\subsubsection{Creación NIF E}

NIF E-2. Donativos recibidos u otorgados por entidades con propósitos no lucrativos. El CINIF decidió emitir la NIF E-2 con el objetivo de incorporar la nueva terminología establecida en el Marco Conceptual de las NIF, en especial en las NIF A-3 y A-5; además, los cambios en la NIF E-2 tienen como finalidad que esta norma sea consistente con la NIF B-16, Estados financieros de entidades con propósitos no lucrativos, dado que ambas tienen la misma fecha de entrada en vigor.

Esta NIF contiene las normas de reconocimiento de los donativos recibidos, así como de los otorgados por las entidades con propósitos no lucrativos.

\subsection{En qué va el proceso de elaboración de las NIF}

Después de hacer una revisión a la normatividad internacional vigente, el país azteca decide promulgar el libro de las NIF, edición 2006, en este texto los contadores públicos tenían la oportunidad de ver la normatividad financiera para su país en un sólido compilado de 5 series que tratan la normatividad más importante en temas contables. Posteriormente se han publicado de manera permanente las diferentes NIF aprobadas con voto aprobatorio de más del $60 \%$ del grupo de los investigadores del CID con derecho a votar.

El docente de la Universidad de Colima, Martín Álvarez Ochoa, considera que "el proceso de implementación de las NIF entró en vigencia a partir del año 2006 y sólo estaba listo el marco conceptual y la NIF B-1 "Cambios contables y correcciones de errores y que las series $B, C, D, E$, han sido intermitentes de 2007 a 2010", lo cual implica que México es un país muy conservador en abandonar los PCGA, sin embargo, se puede decir que las NIF se implementan en un $90 \%$, sin periodo de transición". (Álvarez, 2010).

Las Normas de Información Financiera, NIF, son el equivalente a los Principios de Contabilidad Generalmente Aceptados, estas normas son la carta de navegación que existe en México para realizar cualquier tipo de operación contable o financiera. Según el contador público y docente mexicano Alfredo Martínez Cobos "las NIF comprenden un conjunto de conceptos generales y normas particulares que regulan la elaboración y presentación de la información financiera contenida en los estados financieros, y que son aceptadas de manera generalizada en un lugar y a una fecha determinada" (Martínez, 2010).

EI CINIF ha realizado un gran esfuerzo para lograr un proceso de convergencia entre las NIFy las NIIF, el trabajo se ha centrado en obtener marcos contables comunes que permitan cierta "uniformidad y convergencia para lograr adaptar o adoptar normas" (Motta, 2010).

En México, este proceso de convergencia entre las normas internacionales y locales, ha establecido que las NIF mexicanas son revisadas y comparadas con las NIIF, además, señala a las normas internacionales como base para crear las normas nacionales, aspectos que sumados pretenden mejorar la solución contable para incrementar la transparencia en los procesos financieros.

De igual forma, una vez puesta en marcha las NIF, sufren un proceso de revisión y validación, en caso que sea necesario, el CINIF plantea las mejoras a la NIF, incluyendo sus párrafos de vigencia y transitorios, para especificar la fecha de entrada en vigor de cada mejora. Los cambios se incorporarán en cada una de las NIF correspondientes, con la finalidad de actualizar dichas normas; asimismo, en cada NIF que se modifique se incluirá una mención que evidencie que se ha llevado a cabo una modificación en ese párrafo como consecuencia de la revisión de esa norma.

México continúa el proceso de elaboración de las NIF presentando proyectos de auscultación. De igual forma, presenta mejoras a las NIF debido a que los organismos emisores de normatividad contable resaltan la importancia de dar seguimiento a las NIF ya emitidas puesto que éstas se encuentran en constante evolución con la intención de que estén actualizadas basadas en estándares y normatividad internacional. 
Respecto a la implementación de las NIF en México el Dr. Martin Alvarez Ochoa director de la Facultad de Contabilidad y Administración de la Universidad de Colima señala que "La incorporación del cuerpo normativo se hace sin un proceso de transición previo, simplemente, se dejaron de usar los principios sin más ajustes que los que pudiera implicar. Todo ello por la comparación de estados financieros, lo que ha provocado en los diferentes sectores incertidumbre; sobre todo porque aparecieron dos regulaciones nuevas, las de corte cualitativo NIF A4 y las de corte de valuación de empresas la NIF A6, lo anterior, sin considerar la diversidad de las necesidades de los sectores productivos. El proceso de transición, incluso en el ejercicio, pasó desapercibido, porque la diferencia con los Principios de Contabilidad en realidad si son muy marcados y al momento de la comparación de Estados financieros con ejercicios anteriores se refleja de manera muy pero muy significativa” (Álvarez, 2010).

“En términos generales, el 1 de enero de 2011 será la fecha de transición de las NIIF y el 31 de diciembre de 2012 será la fecha de presentación del informe según las NIF para todas las empresas mexicanas, con excepción de las entidades del sector financiero y asegurador reguladas por la Comisión Nacional Bancaria y de Valores CNBV y para las empresas que cotizan en bolsa, debido a que estas en su mayoría han logrado la conversión a NIIF" (KPMG, 2009). Hasta ahora, tres emisoras mexicanas (América Móvil, Mexichem y Benavides) optaron por anticiparse a la aplicación de estas normas desde este año, mientras que 18 más anunciaron que a partir de 2011 aplicarán de forma anticipada las reglas financieras señalando que en el mercado accionario cotizan alrededor de 130 emisoras (CNNEXPANSION, 2010).

\subsubsection{Mejoras a las normas de información financiera}

El CINIF emite un documento llamado "Mejoras a las normas de información financiera" "Mejoras a las NIF" que tiene como objetivo hacer cambios y precisiones a las normas de información financiera (NIF) vigentes con la finalidad de establecer un planteamiento normativo más adecuado.

Las mejoras a las NIF se presentan clasificadas en dos secciones:

* Sección mejoras a las NIF que generan cambios contables, son propuestas de modificaciones a las NIF que de acuerdo con la NIF B-1 generan cambios contables en evaluación, presentación o revelación en los estados financieros de las entidades.

* Sección mejoras a las NIF que no generan cambios contables, son propuestas de modificaciones a las NIF para hacer precisiones a las mismas que ayuden a establecer un planteamiento normativo más claro y comprensible, por ser precisiones no generan cambios contables en los estados financieros de las entidades.

\section{Figura 7. Mejoras a las NIF 2011}

\section{Mejoras a las NIF 2011}

Fue auscultado en septiembre de 2010 e incluye cambios puntuales en las NIF que son sugeridas por parte de los interesados en la información financiera como consecuencia de la aplicación de las normas y de la revisión que el propio CINIF hace a las NIF.

Los cambios elimininan algunas diferencias con las Normas Internacionales de Información Financiera (NIIF - IFRS por sus siglas en inglés).

Las modificaciones estarán incorporadas en el libro NIF 2011 en cada una de las NIF correspondientes, con la finalidad de actualizarlas.

Cada NIF modificada se incluirá una mención que evidencie que se ha llevado a cabo una modificación en ese párrafo como consecuencia de la revisión de esa norma.

Fuente: elaboración propia.

\subsubsection{Esfuerzos de la convergencia a NIIF}

Las diferencias más notorias entre las NIF y las NIIF se dan, en una primera parte, en torno a la revelación y presentación de información, por ejemplo, en la revelación en los segmentos geográficos bajo las NIF se revela el monto de ciertos rubros básicos de la entidad geográfica, como son las ventas por segmentos y la utilidad de operación, entre otros, a diferencia de las NIIF donde se necesita revelar un estado de resultados por entidad geográfica. Es de notar así la exigencia marcada en este aspecto según los criterios del IASB. A continuación el Cuadro 1. Resume las principales diferencias entre estos dos cuerpos normativos: 


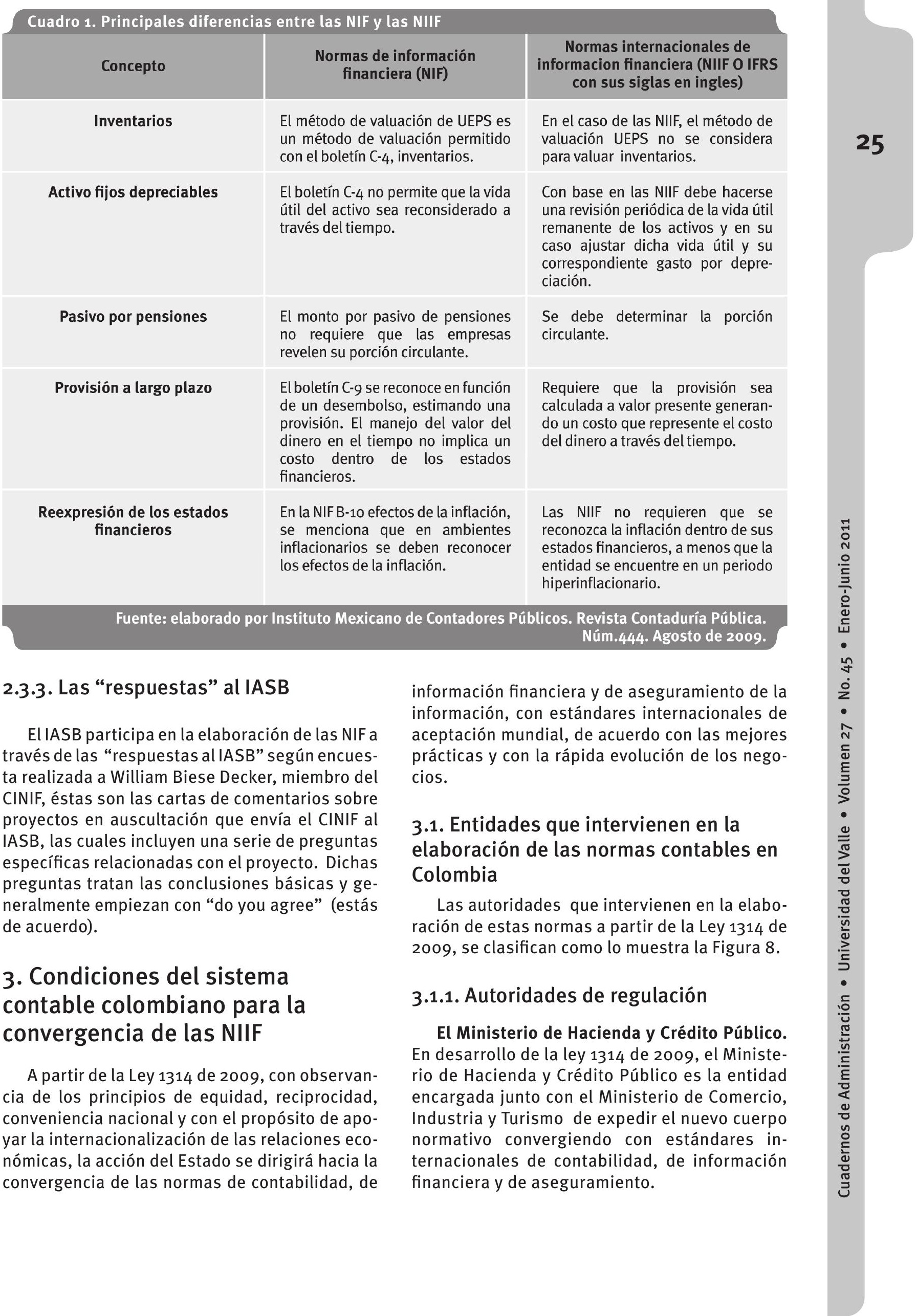




\section{Entidades que intervienen en la elaboración de las normas contables en Colombia}

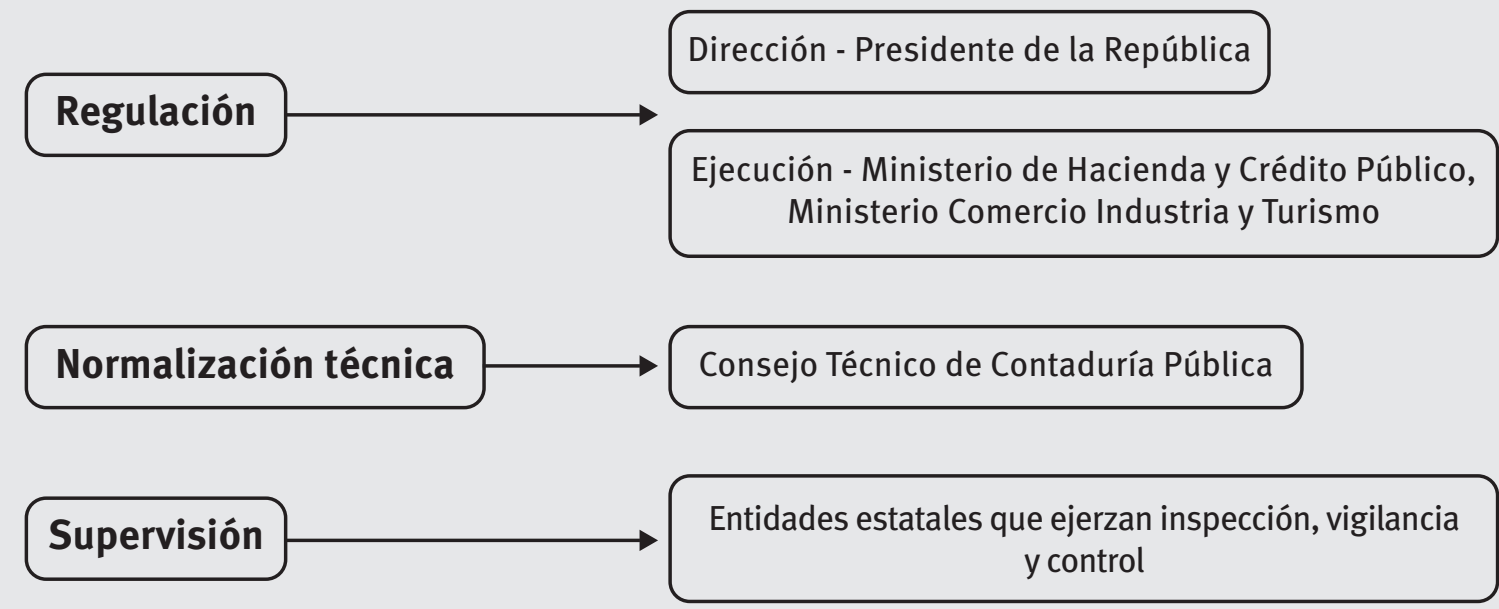

Fuente: elaboración propia.

El Ministerio de Comercio, Industria y Turismo. Con la promulgación de la Ley 1151 de 2007, el Honorable Congreso de la República, cambió la adscripción de los órganos de la profesión contable: la Junta Central de Contadores y el Consejo Técnico de la Contaduría Pública del Ministerio de Educación Nacional pasó al Ministerio de Comercio, Industria y Turismo, con el fin de darle a este Ministerio el control administrativo, al que se refiere el artículo 104 de la Ley 489 de 1998. Según lo dispone el mencionado Plan Nacional de Desarrollo, estas funciones se desarrollarán en consonancia con las políticas gubernamentales de control a los agentes de mercado y de incremento de la competitividad del país. Así mismo, el Decreto 2700 del 23 de julio del 2008, que modificó el Decreto 210 del 2003, ratifica ésta decisión.

\subsubsection{Autoridades de normalización técnica}

El Consejo Técnico de la Contaduría Pública (CTCP). De acuerdo a los artículos 6 y 7 de la Ley 1314 de 2009, se convierte en el organismo de normalización técnica de normas contables, de información financiera y de aseguramiento de la información. En concordancia el Decreto 691 de 2010 señala: el Consejo Técnico de la Contaduría Pública es un organismo permanente de normalización técnica de normas contables, de información financiera y de aseguramiento de la información, adscrito al Ministerio de Comercio, Industria y Turismo.
Cabe resaltar que en el mes de febrero del año 2008 , el CTCP a través de la orientación profesional del 14 de febrero, señaló que los pronunciamientos o disposiciones profesionales deben desaparecer del universo jurídico, dado que se derivan de textos de normas declarados inconstitucionales, cambiando su posición respecto a la consagrada en la Orientación 2 del 2000, en la cual expresaba que estas disposiciones eran doctrina general orientadora y no vinculante. El Consejo advierte que dentro del "programa de desarrollo doctrinal contable" emitirá las nuevas orientaciones profesionales que sean pertinentes. Las nuevas orientaciones emitidas hasta la fecha son:

* Efectos de la Sentencia C- 530 del 2000 relativa a la constitucionalidad de algunas disposiciones de la Ley 43 de 1990 (Febrero 14 /2008).

* Ejercicio profesional de la contaduría pública en entidades de propiedad horizontal (Febrero 26/ 2008).

* Ejercicio profesional de la revisoría fiscal (12 junio/2008).

* Presentación de estados financieros basados en estándares internacionales de contabilidad e información financiera a IAS/IFRS (9 de Diciembre/2008, modificada 3 de abril/2009).

* Tarifa de honorarios profesionales (16 de junio/2009). 


\section{Plan de trabajo del Consejo Técnico de la Contaduría Pública (CTCP)}

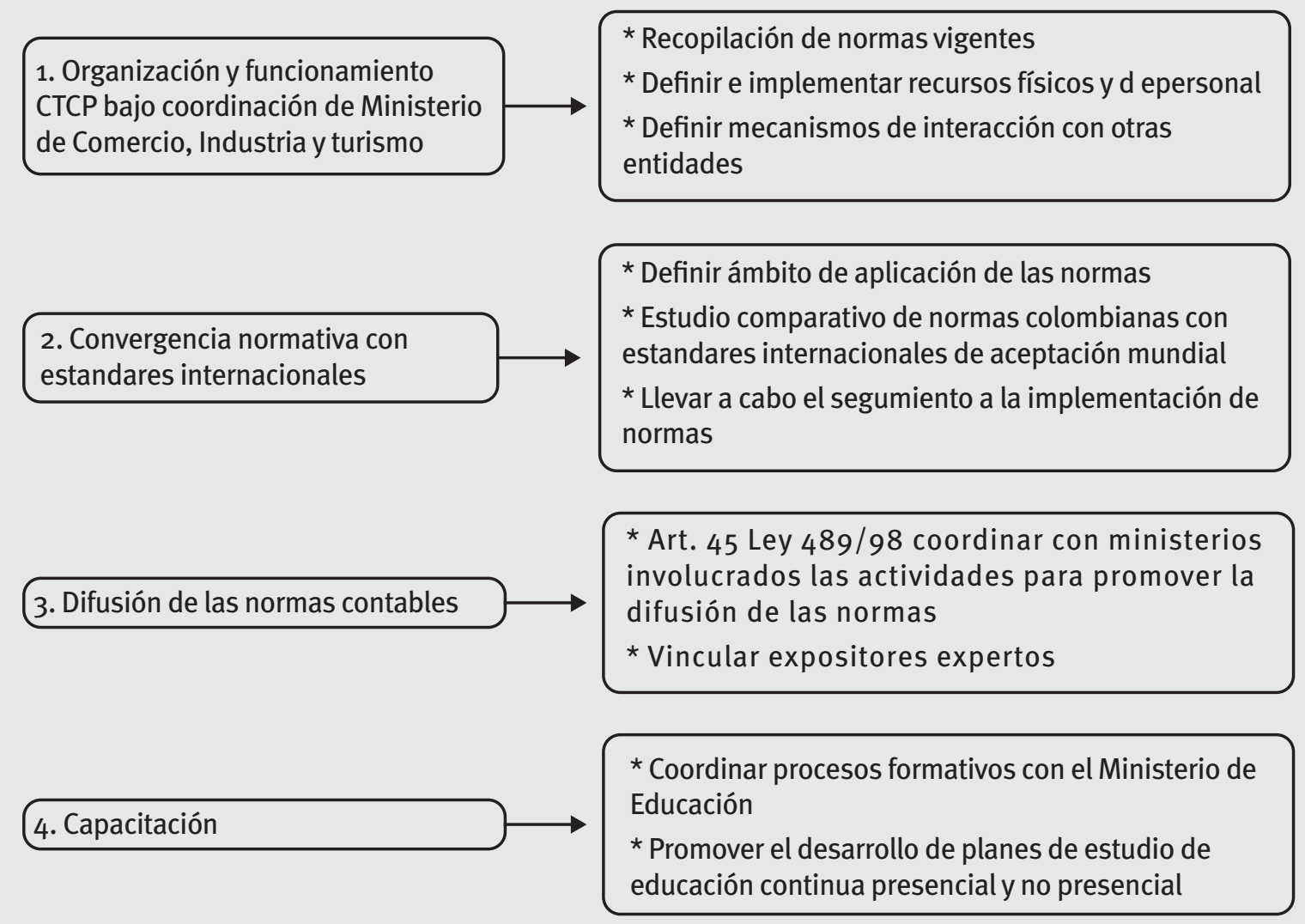

Fuente: elaboración propia.

\subsubsection{Autoridades de Supervisión}

Entidades estatales que ejerzan inspección, vigilancia y control. El artículo 137 del Decreto 2649 del año 1993 dispone que "otras autoridades distintas del Presidente de la República podrán dictar normas contables", en este caso se trata en su mayoría de las superintendecias adscritas a los diferentes ministerios.

\subsection{Plan de trabajo del CTCP}

El Plan de trabajo emprendido por el Consejo Técnico se basa en los siguientes cuatro ejes temáticos (Figura 9).

Como lo deja ver la figura 9, el plan de trabajo elaborado por el CTCP por requerimiento de la Ley 1314 de 2009 pretende "establecer una hoja de ruta que permita llevar a cabo la emisión de normas contables, de información financiera y de aseguramiento de información, mediante un proceso de convergencia a estándares internacionales de la mejor calidad, considerando las instancias efectivas de coordinación, integración y divulgación" (CTCP,
2010). El plazo para dar cumplimiento a este plan es de 24 meses, desde su promulgación.

\section{México, referente en el proceso de convergencia emprendido por Colombia}

El proceso de internacionalización contable emprendido por Colombia en el año 2009 presenta características similares al desarrollado por México desde el año 2002. Es de resaltar el ánimo de convergencia de los dos países, las funciones similares de los entes normalizadores y la decisión unánime de involucrar a la comunidad contable en el proceso.

Respecto a los entes, en Colombia el Consejo Técnico de la Contaduría Pública presenta funciones similares a las desarrolladas por el CINIF (Consejo Mexicano para Investigación y Desarrollo de Normas de Información Financiera). No obstante, se presentan diferencias en cuanto a su conformación y origen, así: 
Constituido en el 2002 por entidades líderes del sector público y privado

Organismo independiente en su desarrollo y operación

Desarrolla las NIF en armonía con las NIIF
Se rige por el decreto 691 del 4 de marzo del 2010, y pertenece al sector público, rama ejecutiva.

Organismo permanente de normalización técnica de normas contables, adscrito al Ministerio de Comercio, Industria y Turismo.

Desarrolla la normatividad contable buscando la convergencia a NIIF (Artículo 1 Ley 1314 de 2009)

Su estructura organizacional la conforman el Comité de Vigilancia, la asamblea de asociados el comité de nominación, el Consejo Directivo, el Comité Técnico Consultivo y el CID.
Conformado por cuatro miembros, tres de los cuales serán contadores públicos designados por el Presidente de la República, el Ministro de Comercio Industria y Turismo y el Ministro de Hacienda y Crédito Público.

Fuente: elaboración propia.

Es importante resaltar que el CINIF tiene el propósito de investigar, desarrollar y difundir principios y normas que regulen la información financiera. Con ello se facilitará la comunicación entre los distintos actores del medio financiero y se hará más eficiente y productiva la inserción de México en la economía global. Mientras el Consejo Técnico de la Contaduría Pública de Colombia es el órgano asesor y consultor de normatividad contable catalogado como el máximo órgano de dirección y orientación técnica científica de la profesión.

En México de igual forma se logra así unificar la normatividad contable, armonizando los diversos sectores económicos del país.

De esta manera, el proceso de convergencia de las NIF es un referente valioso porque México demuestra ser capaz de crear su propia normatividad sin alejarse de los estándares internacionales, adecuándola exclusivamente a las necesidades del país.

\subsection{Proceso de México como referente para la convergencia contable colombiana}

La formulación de las NIF (Normas de Información Financiera de México) deja ver cómo la soberanía normativa de los países puede defenderse y lograr la creación de un cuerpo normativo, que sin alejarse de los estándares mínimos exigidos a nivel internacional, tenga en cuenta el contexto propio del país (en este caso de las NIIF, Normas Internacionales de In- formación Financiera emitidas por la IASB Junta de normas internacionales de contabilidad).

El proceso desarrollado por México presenta grandes beneficios para las empresas, un ejemplo claro es que permite que la información financiera presentada bajo estándares internacionales sea percibida como una información de mayor calidad tanto para los usuarios de la información como para, inversionistas, además, permite la consolidación entre empresas multinacionales permitiendo que su acceso sea más fácil y con costos bajos debido a que la información será regida por una sola norma, por los cual es importante resaltar que los resultados de las operaciones y los rendimientos financieros se podrán comparar sin dificultad alguna.

Se conoce que en México algunas empresas han terminado su proceso de convergencia a NIIF con resultados, han sido satisfactorios, resaltando que estas tienen nexos con empresas europeas y norteamericanas por lo que no han tenido dificultad alguna en el lenguaje contable, por lo tanto, se considera que el papel realizado por el CINIF es muy importante en la emisión de normas de información financiera, debido a que con la tendencia mundial y los procesos de globalización México ha logrado unificar la normatividad contable, armonizando los diversos sectores económicos del país.

De esta manera, el proceso emprendido por el CTCP es un reto para la profesión contable y, de acuerdo a lo expuesto en este documento, aunque se trata de una tarea compleja y no exenta de dificultades, es realizable. El reto más importante debe comenzar con la capacitación de los usuarios de la 
información, contadores públicos y comunidad en general, quienes deben comprender y estudiar los cambios en la nueva normatividad contable para poder competir profesional, económica y globalmente en los diferentes sectores económicos.

Es de resaltar como en México el hecho de manejar normas armonizadas bajo los estándares internacionales facilita el otorgamiento de préstamos para empresas mexicanas y reduce el costo de financiamiento que se obtiene de otros países. "El beneficio para las compañías mexicanas de aplicar estas normas, es que los inversionistas extranjeros ya no tendrán que pensar en normas financieras distintas entre las que prevalecen en México y las que se establecen en el ámbito internacional" (Pérez Cervantes, 2010), situación que beneficiaría a Colombia una vez logre la convergencia contable.

\section{Conclusiones}

* México y Colombia son los países de América Latina que han emprendido un proceso de convergencia a Normas Internacionales de Información Financiera, de origen europeo (NIIF elaboradas por el IASB).

* La formulación de las NIF (Normas de Información Financiera de México) es un ejemplo claro de cómo la soberanía normativa de los países puede defenderse y lograr la creación de un cuerpo normativo que, sin alejarse de los estándares mínimos exigidos a nivel internacional (en este caso de las NIIF Normas Internacionales de Información Financiera emitidas por la IASB Junta de normas internacionales de contabilidad), tenga en cuenta el contexto propio de cada país.

* En Colombia la profesión y el quehacer de los Contadores Públicos se encuentra administrado desde el sector público, de ahí que desde las tres ramas del poder público se direccione gran parte del trabajo del Contador Público, situación que ha causado una dispersión de la información contable producida desde los diferentes sectores económicos del país.

* El caso de convergencia normativo realizado por México es un verdadero referente para el momento que atraviesa la profesión contable colombiana.

* El proceso de elaboración de las NIF presenta las siguientes seis fases: (1) publicación de los proyectos elaborados por el CID, (2) se da paso a las opiniones respecto de cada norma, (3) se indica el plazo que, como mínimo, será de tres meses otorgados por el CINIF para enviar las opiniones, (4) después se realiza la discusión de los documentos mediante foros y conferencias abiertas, (5) los comentarios hechos a través de la WEB se analizan por el CID y el CTC y (6) por último, se da la aprobación de la NIF, respectiva.

* La convergencia contable mexicana muestra claramente como el proceso de auscultación se convierte en una metodología que puede ser aplicable para el proceso emprendido por Colombia, el cual ha permitido a la comunidad contable de México participar en un ejercicio contencioso analizando cambios, ventajas, desventajas de cada una de las NIIF, en discusión.

* El IASB interviene en la elaboración de las NIF a través de cartas que el CINIF le envía, respecto de los proyectos que se encuentran en auscultación, las cuales contienen preguntas puntuales sobre las normas.

* En México, como en la mayoría de los países del mundo, las empresas que cotizan en el mercado público de valores son las compañías obligadas a adoptar el cuerpo normativo emitido por la IASB. En este caso, estas entidades no manejan en ningún caso NIF sino NIIF y el plazo para hacer esta adopción vence el 1 de Enero de 2012.

\section{Referencias}

Consejo Internacional de Normas de Información Financiera. (2009). Puesta en práctica de normas internacionales de información financiera: lecciones aprendidas, estudio de caso de países en las NIIF. Recuperado el 22 de Octubre de 2010 de http://cinif.gov.co

Consejo Técnico de la Contaduría Pública. (2009) Presentación de estados financieros con base en estándares internacionales de contabilidad e Información financiera IAS/ IFRS. p.63.

Colombia. Leyes, decretos, etc. (1990). Ley 43 (13 de diciembre de 1990). Por la cual se adiciona la ley 145 de 1960, reglamentaria de la profesión de contador público y se dictan otras disposiciones. Bogotá: Imprenta Nacional.

Colombia. Leyes, decretos, etc. (1993). Decreto 2649 (29 de diciembre). Por el cual se reglamenta la contabilidad en general y se expiden los principios o normas de contabilidad generalmente 
aceptados en Colombia. Bogotá: Imprenta Nacional.

Colombia. Leyes, decretos, etc. (2009). Ley 1314 (13 de Julio de 2009). Por la cual se regulan los principios y normas de contabilidad e información financiera y de aseguramiento de información. Bogotá: Imprenta Nacional.

Colombia. Leyes, decretos, etc. (2010). Decreto 691 (14 de marzo de 2010). Por el cual se modifica la conformación del Consejo Técnico de la Contaduría Pública y se dictan otras disposiciones. Bogotá: Imprenta Nacional.

Consejo Mexicano para la Investigación y Desarrollo Contable. Comisión de Normas Internacionales de Contabilidad, International Accounting Standards Board. (2006). Normas internacionales de información financiera (NIIF) 2006. IASCF, 2006. Recuperado el 30 de junio de 2010 de http://cinif. gov.co

Instituto Mexicano de Contadores Públicos. (2005). Normas de información financiera. Recuperado el 20 de noviembre de 2009 de http://cinif.gov.co

Instituto Mexicano de Contadores Públicos (2009). Revista de Contaduría Pública. Núm.444.

Marco conceptual. (s.f.). Recuperado el 4 de septiembre de 2009 de http://www.uady. $\mathrm{mx} / \sim$ contadur/files/cuerpoacad/caef/aief/resumen_NIF_marco_conceptual.pdf

Martínez, A. (2009). Normas de información financiera: marco conceptual. Recuperado el 3 de julio de 2010 de http://www.docstoc. com/docs/15369893/Normas-de-InformacionFinanciera--Serie-A-(NIF-Mexico).

Moreno, J. (2005). Historia técnica de la contabilidad y la información financiera. México: Instituto Politécnico Nacional.

Motta, A. (2010). Globalización y herramientas de competencia profesional. Bogotá: Legis.

Montilla, 0. J. (2006). Estándares internacionales de contabilidad y reportes financieros. Armenia.

Muñoz, C. (2009). Retos para la convergencia contable. Ciudad: Bogotá IMEF.
Normas de información financiera NIF B1. (s.f.). Recuperado el 30 de noviembre de 2009 de http:// www.fca.unam.mx/portal-delprofesor/docs/ academias/ auditoria/NIFB1. pdf

Normas de información financiera. (s.f.). Recuperado el 1 de mayo de 2010 de http://clubvirtual. gvaweb.com/admin/curricula/material/05_ NP110_NIF_B-3.pdf

Normas de información financiera. (2007). Recuperado el 1 de mayo de 2010 de http://www.prvmex.com/boletin_financiero_marzo_2007.pdf

Pérez, F. (2011). Convergencia de las NIF con las IFRS. Análisis de las principales diferencias. CINIF.

Romero, E. (2005). Aplicación de normas internacionales de contabilidad. Ciudad: México D.F. CISS.

San, A. (2005). Las normas internacionales de información financiera. México: Thomson.

\section{Abreviaturas}

IMCP: Instituto Mexicano de Contadores Públicos

CINIF: Consejo Mexicano de Normas Información Financiera

\section{CV: Convergencia Contable}

CTCP: Consejo Técnico de la Contaduría Publica

IASB: Junta de Normas Internacionales de Contabilidad

IASC: Comité de Normas Internacionales de Contabilidad

NIIF: Normas Internacionales de Información Financiera

NIF: Normas de Información Financiera de México

CTC: Consejo Técnico Consultivo

CID: Centro de Investigación y Desarrollo

COMPIC: Comité Mexicano para la práctica internacional de la Contaduría 